\title{
Perceived environmental housing quality and wellbeing of movers
}

\author{
S Kahlmeier, C Schindler, L Grize, C Braun-Fahrländer
}

\begin{abstract}
Study objective-To examine whether changes in environmental housing quality influence the wellbeing of movers taking into account other dimensions of housing quality and sociodemographic factors. Design-Cross sectional telephone survey. Associations between changes in satisfaction with 40 housing quality indicators (including environmental quality) and an improvement in self rated health (based on a standardised question) were analysed by multiple logistic regression adjusting for sociodemographic variables. Objective measures of wellbeing or environmental quality were not available.

Setting-North western region of Switzerland including the city of Basel.

Participants-Random sample of 3870 subjects aged 18-70 who had moved in 1997 , participation rate $55.7 \%$.

Results-A gain in self rated health was most strongly predicted by an improved satisfaction with indicators related to the environmental housing quality measured as "location of building" (adjusted odds ratio $(O R)=1.58,95 \%$ confidence intervals (CI) $=1.28,1.96)$ and "perceived air quality" $(\mathrm{OR}=1.58,95 \% \mathrm{CI}=1.24,2.01)$ and to the apartment itself, namely "suitability" $(\mathrm{OR}=1.77,95 \% \mathrm{CI}=1.41,2.23)$, "relationship with neighbours" (OR=1.46, 95\% $\mathrm{CI}=1.19,1.80)$ and "noise from neighbours" (OR=1.32, 95\% CI=1.07, 1.64). The destination of moving and the main reason to move modified some of the associations with environmental indicators.

Conclusion-An improvement in perceived environmental housing quality was conducive to an increase in wellbeing of movers when other dimensions of housing quality and potential confounders were taken into account.
\end{abstract}

(F Epidemiol Community Health 2001;55:708-715)

In many cities in developing countries, inadequate housing, lack of sanitation, dampness or overcrowding endanger the health of inhabitants, especially among economically disadvantaged groups. ${ }^{12}$ In industrialised countries too, relations between housing quality and health were reported. A large body of research focused on specific aspects of housing quality like, for example, dampness and specific health outcomes such as respiratory health. ${ }^{3}$ Others applied a broader concept of housing quality and/or more general concepts of health. For example, Haan et al demonstrated that residence in a poor neighbourhood was associated with an approximately $50 \%$ increase in mortality compared with a non-poverty area. ${ }^{5}$ Yen and Kaplan showed that living in low social environments was associated with both, an increased risk of death ${ }^{6}$ and decreased self rated health. ${ }^{7}$ They also reported an increase in depressive symptoms. Malmström et al found an association between neighbourhood socioeconomic environment and self rated health as well. ${ }^{8}$ Mackenbach et al showed that the presence or absence of housing problems was associated with both ill and excellent health, respectively. ${ }^{9}$ A body of research focused on the impact of housing quality on health and wellbeing among the elderly, showing associations with mortality, ${ }^{10}$ with different measures of wellbeing ${ }^{11}$ with life satisfaction and happiness, ${ }^{12}$ and with self rated health. ${ }^{10}{ }^{13}$ In many of these studies self rated health has served as a useful summary measure of general wellbeing: it is associated with morbidity ${ }^{14}{ }^{15}$ and mortality, ${ }^{16}$ as well as with the use of physician services, ${ }^{17}$ and with mental health. ${ }^{18}$ In addition, self rated health also reflects aspects of social role, self image, ${ }^{19}$ and perceived control. ${ }^{20}$

Because of the growing body of evidence relating housing quality to wellbeing and health, the issue has been politically recognised in industrialised countries too. ${ }^{21-23}$ This resulted in initiatives like the Healthy Cities Project, which was developed in 1986 to apply the Health for All principles at the local level in urban settings. ${ }^{24}$ One of the qualities a Healthy City should aim to provide is a high quality physical environment, including housing quality.

Most of the studies on housing quality, health and wellbeing focused either on very specific single aspects such as dampness and asthma, not allowing conclusions on the overall impact of housing quality on general wellbeing or on proxy measures (like "poverty") or summary indicators of housing quality (like "presence or absence of housing problems in general"). But the question arises as to which of the different aspects of the complex construct "housing quality" are influential for the general wellbeing of citizens. ${ }^{78}$ The environmental quality of the housing surroundings may be an important component and in the public debate, environmental housing quality is often cited as the main driving force for suburbanisation processes. ${ }^{25}$ Within a detailed set of indicators for different dimensions of housing quality, we therefore focused on indicators of environmental housing quality such as perceived noise and perceived air quality. Applying a more general concept of health, we studied if changes in these indicators were predictive of 
changes in self rated health as measure of wellbeing among movers in Switzerland after adjusting for changes in other indicators of housing quality (for example, relating to the apartment itself or to infrastructure) and potential sociodemographic confounders.

\section{Methods}

The study was carried out in the north western region of Switzerland including the city of Basel with approximately 200000 inhabitants. The north western region of Switzerland encompasses an area extending approximately 30 kilometres east and south of Basel with roughly 345000 inhabitants. In summer 1998, a random sample of 3870 non-institutionalised adults, aged 18 to 70 years, with Swiss citizenship or permanent residence permit who had moved once in 1997 either within the city of Basel or out of the city of Basel into the north western region of Switzerland was drawn from the population registry. As this registry contains complete information on address changes, eligible persons could be traced. The random sample, stratified by type of mover (within the city compared with out of the city), was drawn in two stages: firstly, households were selected and secondly, the interview partner within each household was determined. Specially trained interviewers performed the standardised telephone interviews in August and September 1998. For 653 persons (16.9\%) no valid phone number was available, 374 persons $(9.6 \%)$ declined to participate, 282 persons $(7.3 \%)$ did not live at the recorded address anymore, 223 persons $(5.8 \%)$ could not be contacted during the whole interview period within up to 20 attempts, and 181 persons $(4.7 \%)$ could not be interviewed because of other reasons (for example, language). Information was thus obtained from a total of 2157 subjects $(55.7 \%)$.

The questionnaire was based on existing questionnaires, ${ }^{26-28}$ and pretested in a smaller sample. The study was introduced to the participants as a survey on the reasons for moving, the issues presented here were not mentioned. Demographic and socioeconomic information as a potential source of bias was collected on sex, age, household composition, monthly household income, education, and type of moving (details see table 1). Next, participants were asked an open question about the main reason for moving. Answers were noted literally and then, according to prescribed rules, assigned to five main categories: (1) "apartment" (for example, too small/big/ expensive), (2) "personal reasons" (for example, aging, marriage), (3) "neighbourhood" (for example, not suitable for children, problems with neighbours or owner of the house, dirt, no parking space), (4) "environment" (for example, perceived noise or air quality, traffic, not enough green) and (5) "political or social reasons" (for example, school quality, taxes). This question was answered by 2000 participants. For the analyses, the reasons to move were dichotomised into "environmental reasons" (categories 3 and 4) and "other reasons" (categories 1, 2 and 5). Participants were then asked about their present self rated health and the change in self rated health was assessed with the question: "And how is that in comparison to your former residence. Do you now feel in general better, about the same or worse?". Furthermore, they had to assess 40 indicators of housing quality both for their former and their present residence. Besides the environmental quality, these indicators regarded the apartment itself, infrastructure and community services as well as educational and leisure time opportunities. A complete list of all indicators is given in figure 1 . The Swiss school grading scale being familiar to everyone living in Switzerland, with grades from 1 to 6, was used for the assessment ( 1 =very bad, $6=$ very good, $4=$ sufficient, half grades were allowed).

ANALYSES

The change in self rated health was used as outcome measure. It was dichotomised into the categories "improved" and "not improved" (the latter including "no change" and the small group reporting a deterioration). For each of the 40 housing quality indicators the difference between the actual and the former residence was calculated and likewise dichotomised into "improved" and "not improved". Out of the 2157 respondents, 13 had missing values in the outcome variable. For 1961 subjects we had complete information on outcome and all sociodemographic variables. However, answers were missing on some of the housing quality indicators. But for none of the 40 indicators, subjects with missing information differed significantly from those with no improvement as far as changes in self rated health were concerned. Therefore, missing values were coded as "not improved" in order not to reduce the sample size further. The multivariate analyses were thus based on a total of 1961 subjects.

\section{Descriptive analyses}

The data were first analysed by means of cross tabulations of the change in self rated health (improved/not improved) by sociodemographic variables and by the differences in the housing quality indicators (improved/not improved). The degree of heterogeneity across subgroups was evaluated with the $\chi^{2}$ test and the odds ratios for the cross tabulations were estimated using logistic regression.

\section{Dimensions of housing quality}

Next, we performed a factor analysis (varimax rotation). ${ }^{29}$ The indicators could be grouped into eight dimensions of housing quality (factors). To study the relative importance of these different housing quality dimensions as potential determinants of the change in self rated health (dependent variable), a logistic regression analysis was performed, including the standardised factor scores along with the sociodemographic covariates sex, age, household composition, household income, education, and type of moving. 
Table 1 Sociodemographic characteristics of the sample, association with an improved self rated health (SRH) since having moved and frequency of environmental reasons as main reason to move $(n=2144)$

\begin{tabular}{|c|c|c|c|c|c|c|c|c|c|}
\hline & \multirow{2}{*}{\multicolumn{2}{|c|}{ Total }} & \multirow{2}{*}{\multicolumn{4}{|c|}{ Improved SRH since having moved }} & \multicolumn{3}{|c|}{ Main reason to move } \\
\hline & & & & & & & \multicolumn{2}{|c|}{ Environmental $^{\star}$} & \multirow[b]{2}{*}{$p \ddagger$} \\
\hline & number & $\%$ & number & $\%$ & $O R$ & $95 \% C I$ & numbert & $\%$ & \\
\hline Total & 2144 & 100.0 & 1230 & 57.4 & & & 428 & 21.4 & \\
\hline \multicolumn{10}{|l|}{ Sex } \\
\hline Men & 1022 & 52.3 & 555 & 54.3 & 1.00 & & 208 & 21.8 & \\
\hline Women & 1122 & 47.7 & 675 & 60.2 & 1.27 & $1.07,1.51$ & 220 & 21.1 & 0.709 \\
\hline \multicolumn{10}{|l|}{ Age $(y)$} \\
\hline $18-30$ & 796 & 37.1 & 439 & 55.2 & 1.00 & & 120 & 16.3 & \\
\hline $31-45$ & 930 & 43.4 & 528 & 56.8 & 1.07 & $0.88,1.29$ & 209 & 23.8 & \\
\hline $46-60$ & 321 & 15.0 & 204 & 63.6 & 1.42 & $1.09,1.85$ & 78 & 26.3 & \\
\hline $61-70$ & 97 & 4.5 & 59 & 60.8 & 1.26 & $0.82,1.94$ & 21 & 24.1 & $<0.001$ \\
\hline \multicolumn{10}{|l|}{ Household composition } \\
\hline single adult & 700 & 32.7 & 388 & 55.4 & 1.00 & & 134 & 20.7 & \\
\hline $2+$ adults without children & 901 & 42.0 & 501 & 55.6 & 1.01 & $0.83,1.23$ & 158 & 18.7 & \\
\hline $2+$ adults with children & 481 & 22.4 & 300 & 62.4 & 1.33 & $1.05,1.69$ & 120 & 26.5 & \\
\hline single adult with children & 62 & 2.9 & 41 & 66.1 & 1.57 & $0.91,2.71$ & 16 & 28.6 & 0.006 \\
\hline \multicolumn{10}{|l|}{ Household income } \\
\hline$<3000 \mathrm{SFr}$ & 189 & 8.8 & 111 & 58.7 & 1.00 & & 36 & 21.2 & \\
\hline 3000 to $4999 \mathrm{SFr}$ & 472 & 22.0 & 269 & 57.0 & 1.22 & $0.86,1.74$ & 93 & 21.6 & \\
\hline 5000 to $7499 \mathrm{SFr}$ & 564 & 26.3 & 331 & 58.7 & 1.14 & $0.87,1.49$ & 126 & 24.0 & \\
\hline 7500 to $9999 \mathrm{SFr}$ & 341 & 15.9 & 199 & 58.4 & 1.22 & $0.94,1.58$ & 62 & 18.7 & \\
\hline$\geqslant 10000 \mathrm{SFr}$ & 398 & 18.6 & 214 & 53.8 & 1.21 & $0.90,1.61$ & 74 & 19.6 & 0.370 \\
\hline missing & 180 & 8.4 & & & & & & & \\
\hline \multicolumn{10}{|l|}{ Education } \\
\hline high & 891 & 41.6 & 475 & 53.3 & 1.00 & & 153 & 18.7 & \\
\hline middle & 1074 & 50.1 & 650 & 60.5 & 1.34 & $1.12,1.61$ & 236 & 23.4 & \\
\hline low & 164 & 7.6 & 96 & 58.5 & 1.24 & $0.88,1.73$ & 37 & 23.4 & 0.040 \\
\hline missing & 16 & 0.7 & & & & & & & \\
\hline \multicolumn{10}{|l|}{ Type of moving } \\
\hline within the city & 1011 & 47.2 & 539 & 53.3 & 1.00 & & 174 & 18.8 & \\
\hline out of city & 1133 & 52.8 & 691 & 61.0 & 1.37 & $1.15,1.63$ & 254 & 23.7 & 0.008 \\
\hline
\end{tabular}

*Compared with "other reasons"; includes the categories "environment" (for example, noise, traffic, not enough green) and "neighbourhood" (for example, suitability for children, problems with neighbours, dirt). †Based on a total of 2000 answers on the main reason to move. $\ddagger \chi^{2}$ test.

Logistic regression of individual housing quality indicators

Subsequently, we evaluated which of the 40 single indicators were most influential for a change in self rated health. Starting from a logistic regression model including the sociodemographic covariates and all 40 housing quality indicators, we eliminated indicators with $\mathrm{p}$ values $>0.20$. This resulted in a final model with 14 indicators (question verbatim see appendix).

\section{Logistic regression in subgroups}

To investigate whether associations between changes in self rated health and changes in "environmental" housing quality indicators were different between those who moved within the city as compared with those who moved out of the city or between those who moved for "environmental reasons" compared with those who moved for "other reasons", we ran stratified logistic regression analyses. Effect modification was evaluated with the $\chi^{2}$ test for heterogeneity of estimates. With the same approach, we also studied whether moving from a multiple dwelling into a single family home, or owning the house or apartment since having moved modified the associations. The statistical software package SYSTAT $7.0^{30}$ was used to perform the analyses.

\section{Results}

The majority of the subjects (1230 of the 2144 participants, $57.4 \%$ ) stated that in general their self rated health had improved compared with their former residence. Some 829 subjects $(38.7 \%)$ reported no change and only a proportion of 3.9\% (85 participants) reported a deterioration. An overview of the sociodemographic characteristics of the sample and of the associations with an improved self rated health since having moved is given in table 1 .

Subjects who had moved out of the city, women, respondents with a middle education, respondents (two or more) with children and the 46 to 60 year olds were more likely to state that, in general, their self rated health had improved since they had moved. As also shown in table 1, some differences across sociodemographic subgroups were also found regarding the main reason to move: "environmental reasons" were mentioned more often by persons having moved out of the city, participants with children, participants with low or middle education, and in the age groups over 30 .

DIMENSIONS OF HOUSING QUALITY AND IMPROVED SELF RATED HEALTH A factor analysis was performed to study groupings of the 40 indicators. Figure 1 shows the eight dimensions of housing quality having been identified. The label assigned to each factor intends to describe the respective dimension (fig 1). The presented model explained $48.7 \%$ of the total variance in the 40 indicators.

Improved self rated health was most strongly associated with an improved satisfaction with the two dimensions directly relating to the dwelling, namely the dimension "Apartment or building" (adjusted OR 1.55; 95\% CI 1.40, 1.71 ) and the "Apartment related social components" (1.52; 1.37, 1.67), followed by an 


\begin{tabular}{|l|}
\hline \multicolumn{1}{|c|}{ Suitability for children } \\
- suitability of surroundings for children $(0.85)$ \\
- suitability of surroundings for teenagers $(0.80)$ \\
- institutionalised day care (0.62) \\
- private day care (0.56) \\
- school/kindergarten (0.75) \\
- availability of playgrounds (0.79) \\
- way to school $(0.50)$
\end{tabular}

\section{Apartment or building}

- comfort of apartment (0.77)

- suitability of the apartment (0.61)

- condition of the apartment (0.83)

- condition of the building (0.77)

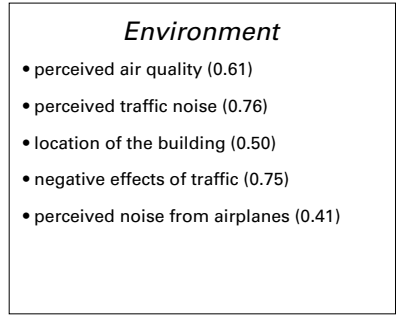

Cultural and social life

- cultural life (0.63)

- possibilities to go out (0.78)

- organised home care (0.41)

- possibilities for adult education (0.60)

- clubs/associations (0.49)

- meeting places/community centres $(0.51)$

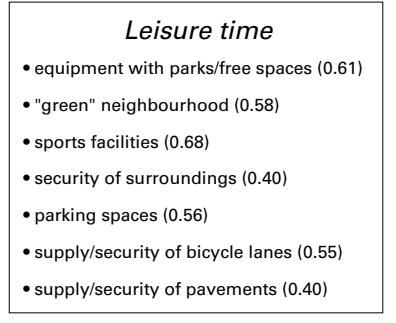

Community services

- waste removal (0.65)

- maintenance of streets (0.65)

- cleanliness of surroundings (0.44)

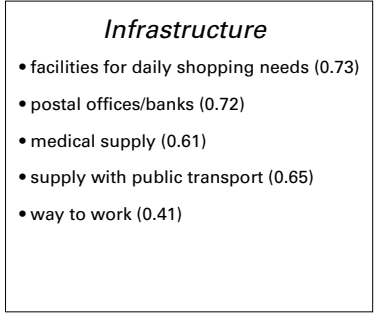

Apartment related social components

- rent/mortgage (0.61)

- relationship with neighbours $(0.63)$

- noise from neighbours $(0.46)$

Figure1 Results of the factor analysis: eight dimensions of housing quality with the corresponding variables and factor loads (in parentheses) ( $n=2157)$.

improved assessment of the dimension "Environment" $(1.47 ; 1.33,1.63)$ and aspects relating to "Leisure time" $(1.39 ; 1.25,1.55)$. An increased satisfaction with the dimensions "Suitability for children" (1.24; 1.04, 1.48), "Community services" (1.17; 1.06, 1.29), "Infrastructure" $(1.16 ; 1.04,1.28)$ and "Cultural and social life" $(1.12 ; 1.01,1.24)$, respectively, showed weaker associations with an improvement in self rated health since having moved.

INDIVIDUAL HOUSING QUALITY INDICATORS AND IMPROVED SELF RATED HEALTH

Table 2 shows the odds ratios for an improved self rated health associated with a higher satisfaction with the remaining 14 single indicators (out of the originally 40, see appendix) since having moved. The indicators are grouped

Table 2 Association between an improved satisfaction with housing quality indicators at the new residence and an improvement in self rated health (SRH) since having moved

\begin{tabular}{|c|c|c|c|c|c|c|}
\hline \multirow[b]{3}{*}{ Improved satisfaction with: ${ }^{*}$} & \multirow{2}{*}{\multicolumn{2}{|c|}{$\begin{array}{l}\text { Total } \\
(n=2144)\end{array}$}} & \multicolumn{4}{|c|}{$\begin{array}{l}\text { Improved SRH since having moved } \\
(n=1961)\end{array}$} \\
\hline & & & \multicolumn{2}{|c|}{ Unadjusted } & \multicolumn{2}{|c|}{ Adjusted $\neq$} \\
\hline & number & $\%$ & $O R$ & $95 \% C I$ & OR & $95 \% C I$ \\
\hline \multicolumn{7}{|l|}{ Environment† } \\
\hline location of the building & 1292 & 60.3 & 2.64 & $2.21,3.15$ & 1.58 & $1.28,1.96$ \\
\hline perceived air quality & 1237 & 57.7 & 2.38 & $2.00,2.84$ & 1.58 & $1.24,2.01$ \\
\hline \multicolumn{7}{|l|}{ Apartment or building $\dagger$} \\
\hline suitability of the apartment & 1352 & 63.1 & 2.81 & $2.35,3.37$ & 1.77 & $1.41,2.23$ \\
\hline comfort of the apartment & 1414 & 66.0 & 2.18 & $1.82,2.61$ & 1.26 & $0.98,1.62$ \\
\hline condition of the apartment & 1225 & 57.1 & 2.07 & $1.74,2.47$ & 1.19 & $0.95,1.50$ \\
\hline \multicolumn{7}{|c|}{ Apartment related social components $\dagger$} \\
\hline relationship with neighbours & 951 & 44.4 & 2.30 & $1.93,2.75$ & 1.46 & $1.19,1.80$ \\
\hline perceived noise from neighbours & 993 & 46.3 & 2.26 & $1.90,2.70$ & 1.32 & $1.07,1.64$ \\
\hline rent/mortgage & 936 & 43.7 & 1.49 & $1.25,1.77$ & 1.16 & $0.95,1.42$ \\
\hline \multicolumn{7}{|l|}{ Suitability for children $\dagger$} \\
\hline \multicolumn{7}{|l|}{ Cultural and social life $†$} \\
\hline clubs/associations in neighbourhood & 455 & 21.2 & 1.93 & $1.55,2.41$ & 1.28 & $0.99,1.65$ \\
\hline $\begin{array}{l}\text { Community services } \dagger \\
\text { cleanliness of the surroundings }\end{array}$ & 1050 & 51.0 & 2.16 & $1.82,2.58$ & 1.24 & $0.99,1.56$ \\
\hline \multicolumn{7}{|l|}{ Infrastructure $\nmid$} \\
\hline medical supply & 412 & 19.2 & 1.49 & $1.19,1.86$ & 1.23 & $0.93,1.62$ \\
\hline facilities for daily shopping & 615 & 28.7 & 1.33 & $1.10,1.61$ & 1.22 & $0.96,1.54$ \\
\hline \multicolumn{7}{|l|}{ Leisure time } \\
\hline supply/security of sidewalks & 640 & 29.9 & 2.01 & $1.65,2.44$ & 1.21 & $0.96,1.54$ \\
\hline
\end{tabular}

*Compared with "not improved". +Grouping and labels derived from the factor analysis as shown in figure 1. $\ddagger$ Adjusted for all indicators presented and for sex, age, household composition and income, education, and type of moving. according to the results of the factor analyses (see fig 1).

In the multivariate analyses, all associations were weaker than in the bivariate analyses and some associations even became borderline or non-significant. Nevertheless, five indicators remained significantly associated with an improved self rated health: In addition to the two "environmental" indicators "location of the building" and "perceived air quality" these included "suitability of the apartment", "relationship with neighbours" and "perceived noise from neighbours".

ENVIRONMENTAL HOUSING QUALITY INDICATORS AND IMPROVED SELF RATED HEALTH IN SUBGROUPS

Subsequently, we investigated if the associations with the two "environmental" indicators "perceived air quality" and "location of the building" were modified by the main reason to move, the type of moving or whether participants had moved from a multiple dwelling into a single family home or had become a house owner. In table 3, the results of the stratified logistic regression analyses are presented.

Among the less than $15 \%$ of participants who had moved into a single family home, improved self rated health was more strongly associated with a more favourable assessment of the "perceived air quality" than among the remaining subjects. Becoming a house owner did not change the associations materially, moreover the respective subgroup was small (results not shown).

"Type of moving" also modified the association with "perceived air quality": among subjects having moved out of the city, the odds ratio between an improvement in self rated health and a higher satisfaction with this indicator was twice as high as among within city movers. This association was also stronger in participants who had moved mainly for environmental reasons but it was still statistically significant among those who had moved for other reasons. 
Table 3 Associations between an improvement in self rated health since having moved and an improved satisfaction with the "perceived air quality" and the "location of the building" in different subgroups of movers

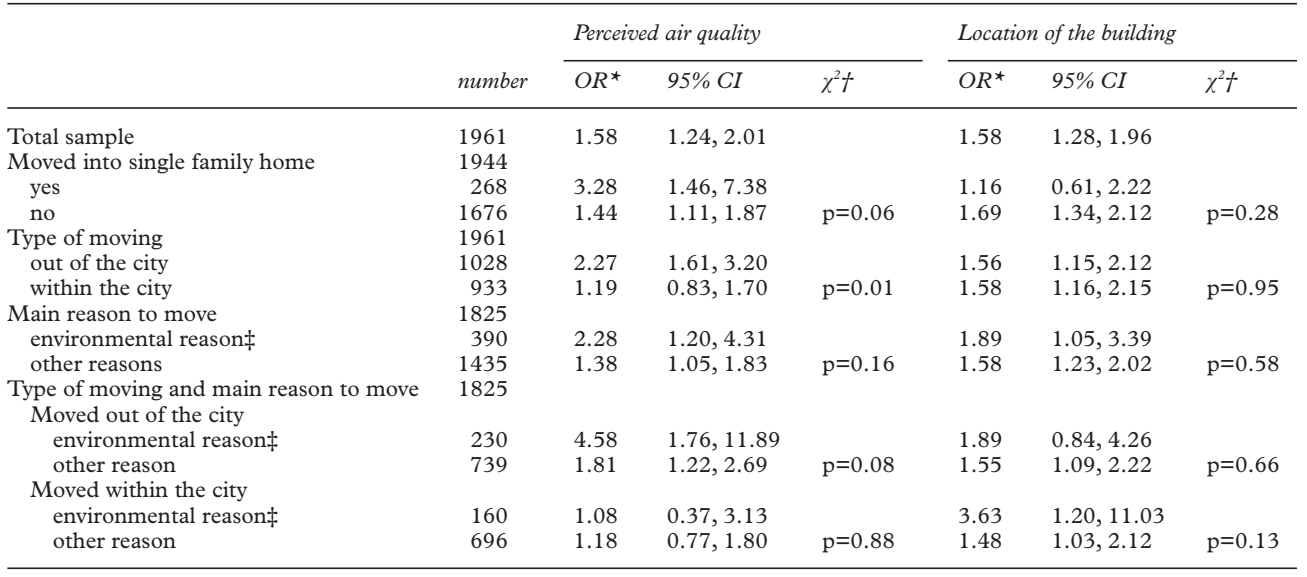

^Final logistic regression model adjusted for sex, age, household composition and income, education, type of moving and all indicators presented in table $2 .+\chi^{2}$ test for heterogeneity of estimates. $\ddagger$ Including the categories "environment" (for example, noise, traffic, not enough green) and "neighbourhood" (for example, suitability for children, problems with neighbours, dirt).

When the analyses were stratified by type of moving and by main reason to move, the association between improved self rated health and a higher satisfaction with the "location of the building" was found in both types of movers, being slightly stronger in those who had moved within the city for environmental reasons. The association with an improved assessment of air quality on the other hand was only found in subjects who had moved out of the city. It was stronger in those having moved out of the city for environmental reasons but still remained significant in those with other reasons.

\section{Discussion}

Our results show that even in an economically well to do country like Switzerland, a higher satisfaction with the environmental quality of the new housing surroundings was associated with an improved well being of movers when other dimensions of housing quality and potential sociodemographic confounders were taken into account even if the subjects had not moved for environmental reasons.

\section{IMPORTANCE OF DIFFERENT DIMENSIONS OF}

HOUSING QUALITY

We found that the satisfaction with the environmental housing quality, with the apartment and with the apartment related social environment were more strongly associated with wellbeing, than were infrastructure indicators, the suitability for children, and the cultural and social life. Only a limited number of previous studies are available to compare these findings with. Most of them either focused on specific aspects of housing quality and health ${ }^{34}$ or used different outcome or exposure measures. Van Poll found that subjective health (based on reported symptoms) was associated with dwelling satisfaction but not with neighbourhood satisfaction. ${ }^{31}$ Lawton found rather similar associations between a perceived positive change in one's life (including health) and interviewer rated ambience of the dwelling, dwelling maintenance and neighbourhood quality. ${ }^{11}$
KEY POINTS

- Housing quality and wellbeing are key issues on political agendas of developing as well as developed countries.

- This study presents an analysis of a detailed set of indicators of housing quality, focusing on environmental housing quality.

- An improved wellbeing of movers was associated with a higher satisfaction with environmental housing quality and the apartment.

- The positive association with environmental indicators was persistent in participants who had moved for other than environmental reasons.

The relative importance of different dimensions of housing quality varies probably across different cultures and social groups. Even though our finding seems plausible, the issue remains complex. Some of the dimensions and respective indicators of housing quality in our study whose associations with an improved self rated health were borderline significant would certainly deserve further investigation. It is also interesting to note that an improved relationship with neighbours and less perceived noise from neighbours, reflecting the apartment related social environment, seem to be just as important for an improved wellbeing of movers as the physical characteristics of the apartment itself.

ENVIRONMENTAL HOUSING QUALITY INDICATORS As our research question focused on the environmental housing quality we explored this dimension in more detail. The perception of the two "environmental" indicators "location of the building" and "perceived air quality" probably differed somewhat between individuals and we suppose they stand for two slightly different aspects of the residential environment. None the less, both indicators were 
clearly grouped in the same factor "environment".

The rather global environmental indicator "location of the building" seems to reflect different aspects in the more immediate neighbourhood as next to the association with environmental indicators it was also weakly correlated with, for example, suitability for children, commuting related indicators, supply with infrastructure, and social characteristics of the neighbourhood (however, correlation coefficients were all below 0.3 ). This indicator was associated with an improved wellbeing of movers irrespective of the destination or reason of moving. The immediate neighbourhood therefore seems to be of general importance even though we found an indication that a positively perceived change in this indicator may be more important for an improved wellbeing among subjects who had moved within the city for environmental reasons.

The indicator "perceived air quality" does not entirely reflect the objectively measurable air quality. This indicator should rather be understood as a qualitative evaluation that was also associated with other indicators of environmental quality such as greenness of surroundings as well as noise and negative effects of traffic. It can therefore also be interpreted as a proxy for "environmental quality" in a more general sense. The restriction of the association between the "perceived air quality" and wellbeing to subjects who had moved out of the city is therefore of relevance for the ongoing debate on the reasons of suburbanisation in Switzerland. ${ }^{25}$ As no information on objective measures of environmental quality was available, we cannot determine from our data whether this reflects a real difference in the environmental quality between city and surrounding areas or just different perception between within city movers and out of city movers. That the former is true is suggested by the fact that air pollution was rather uniform within the city of Basel ${ }^{32}$ while somewhat lower concentrations were found at sites surrounding the city. ${ }^{33}$ Thus, the observation of a stronger association among subjects who had moved out of the city supports our interpretation of a change in satisfaction with the "perceived air quality" as reflecting a real difference in the environmental quality, as the achievable degree of perceived improvement was likely to be greater among those subjects.

That among the environmental indicators, an improved satisfaction with "perceived air quality" was most predictive of an improved self rated health certainly also reflects the current political and public debate. In Switzerland, air quality has been a main issue for several years while, for example, noise has received less public attention so far.

TYPE OF MOVING

Having moved into a single family home also increased the association between an improved self rated health and a better assessment of "perceived air quality". However, the increase was only borderline significant and we suspect that having moved into a single family home was less influential than having moved out of the city, as only $14.9 \%$ of the total sample and $23.1 \%$ of the out of city movers actually moved into a single family home.

\section{METHODOLOGICAL CONSIDERATION}

A number of aspects are of relevance for the interpretation of the results. Firstly, it should be noted that even though the response rate was not particularly high participation bias does not seem to be a problem in our study. In most cases, non-participation was attributable to technical reasons. A comparison with data from the statistical office of the canton of Basel regarding sex, age, nationality, and type of moving showed that our sample was representative of the base population except for non-Swiss participants who were slightly underrepresented, especially in the older age groups. The educational level seemed to be rather high compared with the general Swiss population. ${ }^{34}$ However, it was to be expected that the sample might contain more subjects with a higher socioeconomic status. Inhabitants with lower education and income, especially foreigners, are more likely to have difficulties in finding new residences. ${ }^{35-37}$

As shown in the factor analysis, certain clusters of interdependent housing quality indicators were found in our data. Collinearity can lead to difficulties in separating the effects of individual indicators in a multiple regression analysis. This is a possible explanation for the observed weakening of the associations in the multivariate analyses. However, only one correlation between the 14 indicators in the final regression models exceeded 0.50 (suitability and comfort of the apartment: 0.51 ) and only six were above 0.30 . Nevertheless, five associations remained significant in the multivariate analyses.

The simultaneous collection of the information on former and present housing quality may be a source of measurement error leading to an overestimation of the associations presented if recall bias has the same direction for prior housing quality and prior self rated health. Marans concluded however that biases introduced by dissonance reduction (that is, the tendency to avoid conflict between past action and current feelings) were not very large and that they applied rather to general evaluations than to assessments of specific attributes as presented here. ${ }^{38}$ Francescato proposed to use relative degrees of satisfaction as done in this study. ${ }^{39}$ Moreover, as the recall period in our study was relatively short, we consider it as unlikely that recall bias may have been a major source of error.

Whereas "self rated health" is a useful summary measure to study a more general concept of health, its global and subjective character does not permit us to determine which aspects of wellbeing - physical, psychical or social - are most affected by perceived improvements in the housing quality. Unfortunately, additional information on objective health measures to explore this issue further were not available. 
Thus, we also could not control for a change in morbidity or for a decline in functional ability in our subjects, factors that have been shown to influence self rated health. ${ }^{18} 4041$ However, we consider changes in objective health rather as a possible intermediate step than as a potential confounder having influenced the choice of the new residence, particularly as only a small proportion of participants reported a deterioration in self rated health and less than $1 \%$ mentioned health and/or aging as main reason to move.

Even though the cross sectional design of this study does not allow for causal inference, it must be noted that we assessed the change in self rated health and the change in perceived housing quality since having moved, reflecting thus a time interval. So far, only very few longitudinal studies on changes in the satisfaction with housing quality in a broader sense and subsequent changes in wellbeing have been carried out. The few available studies included different age groups and used different dependent variables and indicators for housing quality than our study. ${ }^{71-13}$ Despite our own and a few other results suggesting a causal relation of housing quality on wellbeing, additional longitudinal studies with population based samples covering wider age ranges and using more detailed sets of indicators for housing quality are needed to further elucidate temporality.

Mackenbach and coworkers showed in a cross sectional study that housing problems decreased the probability of excellent self rated health. ${ }^{9}$ They suspected that this association might be an artefact of a propensity to complain because they used few general indicators to measure such a complex construct as "housing quality". ${ }^{42}$ It seems unlikely that the specific and plausible patterns of the reported associations in our study are merely an artefact of general negativism because we used a large set of indicators and individual answering patterns varied substantially. It must also be kept in mind that all subjects in our study had moved and had done so within the same time frame. Therefore, the results cannot be confounded by a "honeymoon" reaction after a change in residence within a subsample. On the other hand, a general improvement in life satisfaction after voluntary moving that might be present in the whole sample cannot explain the heterogeneity of associations across various subgroups of movers. Certainly, subjective assessments of the environment are influenced by personal characteristics as well as by beliefs, emotions, and behavioural intentions. ${ }^{39}{ }^{43}$ The individual response to an adverse environmental situation depends also on appraisal of the source and on, for example, controllability and predictability of the stressor. ${ }^{44}$ Nevertheless, if the impact of housing quality on residents' wellbeing is the target of interest, individual perception is the driving force and should therefore be of interest despite these limitations, unless one is willing to state that "the expert knows better".

In conclusion, our results add to the understanding of a complex issue even though we could not entirely clarify which factor of the housing environment was most influential for an improved wellbeing of movers. However, we showed that perceived environmental quality is an important predictor of well being of citizens. Moreover, the significant associations between perceived improvements in the two environmental indicators "location of the building" and "perceived air quality" and an improved wellbeing in participants who had not moved for environmental reasons certainly deserve attention. Further longitudinal studies on changes of wellbeing should therefore take moving, motivations to do so and subsequent changes in satisfaction with environmental housing quality into account.

\section{Appendix: Question verbatim of the 14 housing quality indicators in the final model (table 2)}

We are now going to name different aspects regarding the housing quality and quality of life and ask you again to give grades between 1 and 6 , first for your present and afterwards for your former residence. 1 is the worst, 6 the best grade, 4 is sufficient, half grades may be given. - air quality (present)/(former)

- noise from neighbours (present)/(former)

- cleanliness of the surroundings (present)/(former)

- comfort of the apartment (size, facilities) (present)/ (former)

- level of the rent or mortgage (present)/(former)

- suitability of the apartment referring to your needs (present)/(former)

- condition of the apartment (present)/(former)

- location of the building referring to your needs (central or quite, green surroundings, etc) (present)/ (former)

- relationship with neighbours (present)/(former)

- facilities for daily shopping needs close by (present)/ (former)

- medical supply, hospitals, pharmacies (present)/ (former)

- institutionalised day care (present)/(former)

- clubs/associations in the surroundings regarding your needs (present)/(former)

- supply and security of pavements (present)/(former)

We would like to thank Dr Madeleine Imhof and Dr Peter Schwendener from the Statistical Office of the canton of Basel-Stadt for the management and provision of the data and we are grateful for the comments of PhD Nino Künzli, PhD Arden Pope and $\mathrm{PhD}$ Nicole Probst-Hensch on earlier drafts of this paper.

Funding: this study was financed by the canton of Basel-Stadt. Conflicts of interest: none.

1 WHO Expert Committee on Environmental Health in Urban Development. Environmental health in urban development: report of a WHO expert committee. Reprinted 1995 edition. Geneva: WHO, 1991.

2 WHO Commission on Health and Environment. Our planet, our health. Geneva: WHO, 1992.

3 Strachan DP, Sanders CH. Damp housing and childhood asthma; respiratory effects of indoor air temperature and asthma; respiratory effects of indoor air temperature and
relative humidity. $\mathcal{F}$ Epidemiol Community Health 1989;43: relative

4 Verhoeff AP, van Strien RT, van Wijnen JH, et al. Damp housing and childhood respiratory symptoms: the role of sensitization to dust mites and molds. Am $\mathcal{f}$ Epidemiol 1995;141:103-10

5 Haan M, Kaplan GA, Camacho T. Poverty and health. Prospective evidence from the Alameda County Study. $A m \mathcal{F}$ Epidemiol 1987;125:989-98.

6 Yen IH, Kaplan GA. Neighborhood social environment and risk of death: multilevel evidence from the Alameda County Study. Am F Epidemiol 1999;149:898-907.

7 Yen IH, Kaplan GA. Poverty area residence and changes in depression and perceived health status: evidence from the Alameda County Study. Int $\mathcal{F}$ Epidemiol 1999;28:90-4.

8 Malmstrom M, Sundquist J, Johansson SE. Neighborhood environment and self-reported health status: a multilevel anvirysis. Am f Public Health 1999;89:1181-6.

9 Mackenbach JP, van den Bos J, Joung IM, et al. The determinants of excellent health: different from the determinants of ill-health? Int F Epidemiol 1994;23:1273-81. 
10 Krause N. Neighborhood deterioration and self-rated health in later life. Psychol Aging 1996;11:342-52.

11 Lawton MP, Brody EM Turner-Massey P. The relationships of environmental factors to changes in well-being. Gerontologist 1978;18:133-7.

12 Carp FM. Impact of improved housing on morale and life satisfaction. Gerontologist 1975;15:511-15.

13 Carp FM. Impact of improved living environment on health and life expectancy. Gerontologist 1977;17:242-9.

14 Krause NM, Jay GM. What do global self-rated health items measure? Med Care 1994;32:930-42.

15 Kaplan GA, Goldberg DE, Everson SA, et al. Perceived health status and morbidity and mortality: evidence from the Kuopio ischaemic heart disease risk factor study. Int $\mathcal{F}$ Epidemiol 1996;25:259-65.

16 Idler EL, Benyamini Y. Self-rated health and mortality: a review of twenty-seven community studies. 7 Health Soc review of twenty-seven

17 Miilunpalo S, Vuori I, Oja P, et al. Self-rated health status as a health measure: the predictive value of self-reported health status on the use of physician services and on morhealth status on the use of physician services and on mortality in the

18 Rodin J, McAvay G. Determinants of change in perceived health in a longitudinal study of older adults. $\mathscr{f}$ Geronto 1992;47:373-84.

19 Smith AM, Shelley JM, Dennerstein L. Self-rated health: biological continuum or social discontinuity? Soc Sci Med 1994;39:77-83.

20 Bobak M, Pikhart H, Hertzman C, et al. Socioeconomic factors, perceived control and self-reported health in Russia. A cross-sectional survey. Soc Sci Med 1998;47:26979.

21 WHO Regionalbüro für Europa. Ziele zur "Gesundheit für alle": die Gesundheitspolitik für Europa. Copenhagen: WHO, 1993.

22 Bertonllini R, Dora C, Krzyzanowski M, et al. Environment and health 1: overview and main european issues. and health 1: overview

23 WHO Regional Office for Europe, editor. Overview of the environment and health in Europe in the 1990s: background environment and health in Europe in the 1990s: background
document. London: Third Ministerial Conference on Envidocument. London: Third Ministerial

24 WHO Regional Office for Europe. Twenty steps for developing an Healthy Cities project. 2nd ed. Copenhagen: WHO, 1995.

25 Baumgartner F. Attraktive und konkurrenzfähige Städte: Kernstadt und Agglomeration-Probleme und Aufgaben einer schweizerischen Agglomerationspolitik. Bern: Bundesamt für Raumplanung, 2000.

26 Statistisches Amt der Stadt Bern.. Stadt Bern: Einwohnerbefragung 1996: Fragebogen. Bern: Link Institut, 1996.

27 Neue Zürcher Zeitung. Immobarometer: Fragebogen. Link Institut im Auftrag der Neuen Zürcher Zeitung. Lucerne: Link Institut, 1998.
28 Bundesamt für Statistik. Schweizer Gesundheitsbefragung 1997: Telefonischer und schriftlicher Fragebogen. Neuchâtel: 1997: Telefonischer und schriftlicher

29 Kleinbaum DG, Kupper LL, Muller KE. Variable reduction and factor analysis. In: Michael P, ed. Applied regression analysis and other multivariable methods. 2nd ed. Boston: PWS-Kent Publishing Company, 1988:595-641.

30 SYSTAT 7.0 for Windows. Standard version. Chicago: SPSS, 1997.

31 van Poll $\mathrm{R}$. The perceived quality of the urban residential environment: a multi-attribute evaluation. [Dissertation]. Groningen: Rijksuniversiteit Groningen, 1997.

32 Röösli M, Braun-Fahrländer C, Künzli N, et al. Spatial varibility of different fractions of particulate matter within an urban environment and between urban and rural sites. $\mathcal{F}$ Air Waste Manag Assoc 2000;50:1115-24.

33 Lufthygieneamt beider Basel. Die Luftbelastung in der Region Basel: Fahresbericht 1999. Liestal: 2000.

34 Bundesamt für Statistik, ed. Statistisches fahrbuch der Schweiz 1998. Zürich: Neue Zürcher Zeitung, 1997.

35 Imhof M. Migration und Stadtentwicklung: Aktualgeographische Untersuchungen in den Basler Quartieren Iselin und Matthäus. Basel: Wepf, 1998

36 Bentham G. Migration and morbidity: implications for geographical studies of disease. Soc Sci Med 1988;26:49-54.

37 Dalgard OS, Tambs K. Urban environment and mental health. A longitudinal study. Br f Psychiatry 1997;171:530-

38 Marans RW. Perceived quality of residential environment. In: Craik KH, Zube EH, eds. Perceiving environmental quality : research and applications. New York: Plenum Press, 1976:123-48.

39 Francescato G, Weidemann S. Evaluating the built environment from the user's point of view: an attitudinal model of residential satisfaction. In: Preiser WFE, ed. Building evaluation. New York: Plenum Press, 1989:181-98.

40 Goldstein MS, Siegel JM, Boyer R. Predicting changes in perceived health status. Am $\mathcal{F}$ Public Health 1984;74:611perceiv.

41 Markides KS, Lee DJ. Predictors of well-being and functioning in older Mexican Americans and Anglos: an eight-year follow-up. F Gerontol 1990;45:S69-73.

42 Mackenbach JP, van de Mheen H, Stronks K. A prospective cohort study investigating the explanation of socioeconomic inequalities in health in The Netherlands. Soc Sci Med 1994;38:299-308.

43 Francescato G, Weidemann S, Anderson JR. Residential satisfaction: its uses and limitations in housing research. In: van Vliet W, Choldin H, Michelson W, et al, eds. Housing and neighborhoods: theoretical and empirical contributions. Westport: Greenwood Press, 1987:43-57.

44 Evans GW, Cohen S. Environmental stress. In: Stokols D, Altmann I, eds. Handbook of environmental psychology. New York: John Wiley, 1987:571-610. 